\title{
USING MOBILE DISASTER RESPONSE SYSTEM IN BRIDGE MANAGEMENT
}

\author{
Ming-Kuan TSAI, Nie-Jia YAU \\ Research Center for Hazard Mitigation and Prevention, National Central University, Taiwan
}

Received 09 Feb 2012; accepted 28 Aug 2012

\begin{abstract}
Over the years, various hydro-meteorological disasters have impacted many countries and civilians, thus decreasing the losses caused by these disasters has become important for disaster management. While bridges often are essential to connect the affected disaster areas, this study focuses on bridge management associated with typhoons and rainstorms. Recently, although numerous information technology-based applications are available, three problems (i.e. asynchronous information records, unsteady information transmission, and inaccessible information analysis) still influence responses on disaster sites. Therefore, this study integrated several mobile information techniques to propose a mobile disaster response system. The applied mobile GPS- and GIS-based data reports simplify information generation, AR-based assistance enhances information representation, and mobile 3D graphics accelerates information processes. Based on the tests, this system not only improved the recognized problems but also strengthened the cooperation between construction engineers and workers and disaster managers. Overall, this study is a useful reference for similar applications in bridge management and disaster management.
\end{abstract}

Keywords: disaster response, bridge management, GPS, GIS, 3D, remote monitoring and surveillance, augmented reality.

\section{Introduction}

Every year, hydro-meteorological disasters (e.g. floods, debris flows, tropical cyclones, and storm surges) cause civilian deaths and tens of billions of dollars in economic losses in many countries, especially in densely-populated cities. In order to decrease the damage produced by these disasters, disaster management has become an important issue worldwide, and many researchers propose various solutions and suggestions. For example, in many cases, government agencies and the related staff should eliminate the probability of damage before the disasters; save lives, minimize damage, and provide assistance during the disasters; and restore the affected areas after the disasters (Federal Emergency Management Agency 2012).

When hydro-meteorological disasters occur, many constructions (e.g. schools, houses, streets, and bridges) are affected. Among these, the bridges are the most important channels for the connection of various disaster areas. If the bridges are impacted, relief work (e.g. offering medical aid, escaping victims, and transporting goods) is delayed so that the damage is increased. Obviously, given the interdependency between bridge management and disaster management, government agencies need to establish numerous response strategies and the correlated staff have to perform these strategies. Therefore, this study focuses on the disaster response in bridge management associated with typhoons and rainstorms.

Based on the life cycle of bridge management, although typhoons and rainstorms have been considered (e.g. referring maximum peak discharge and rainfall dura- tion in the planning and designing stages), the complicated natural variability cannot be prevented completely, particularly in extreme climate conditions. For example, in the United States, 503 bridges failed from 1985 to 2000 (Wardhana, Hadipriono 2003). In these cases, floods cause the most frequent disasters; for instance, a major flood overflowed several states in 1993. In Taiwan, with its special geographical conditions (e.g. fragile hills and rushing rivers), typhoons and rainstorms are two main hydro-meteorological disaster causes. The two disasters caused more than $90 \%$ of the total economic losses from 1985 to 2007 (Chen 2011).

Recently, information technology (IT) has grown rapidly. A number of IT-based applications (e.g. "Global Positioning System (GPS)", "Geographical Information System (GIS)", remote monitoring sensors and surveillance facilities, computer simulation, and "ThreeDimensional (3D)" graphics) have been widely adopted in disaster management. However, during typhoons and rainstorms, when construction engineers and workers participate in bridge management on disaster sites, they still have difficulty on the IT-based applications. Therefore, this study constructs a mobile disaster response system to assist construction engineers and workers to effectively perform the disaster response.

The rest of this study is as follows. Section 1 reviews the information techniques used for disaster response in bridge management. Section 2 recognizes three problems that affect disaster response on disaster sites. In order to improve the three problems, Section 3 proposes an approach. Section 4 implements the approach. After 
Section 5 tests the approach in a case study, Section 6 discusses the test results. The final concludes the findings. Totally, this study is a useful reference for similar applications in bridge management and disaster management.

\section{Literature review}

For current development of disaster response in bridge management, this study describes the commonly used information techniques.

- GPS and GIS: Disaster management relies on many spatial analyses, since disaster managers have to preferentially confirm the details of the disasters (e.g. categories, sources, and locations). For the necessary spatial analyses, GPS is convenient to identify the locations of the affected objects and GIS is simple to process the obtained spatial data. Therefore, the integration of the two techniques helps to solve complex disaster problems (Chen et al. 2011). For example, a bureau of meteorology reports the determined typhoons and rainstorms through GPS. When receiving the spatial data (e.g. longitude and latitude), disaster managers could use GIS to check the correlative information (e.g. the nearby environments and population, as well as the availability of relief resources), and make decisions for the disaster response (e.g. blocking out the dangerous areas).

Some studies also point out the advantages of GPS and GIS for disaster response in bridge management. For example, Wong et al. (2001) applied 29 dual frequency GPS receivers and a Structural Health Monitoring (SHM)-based system for the three major cable-stayed bridges in Hong Kong, and reported that the accuracy of a single epoch was around one centimeter in horizontal direction and two centimeters in vertical direction. In order to assist inspectors to make on-site deterioration evaluation, Hammad et al. (2006) integrated GPS, GIS, and 3D graphics to propose a location-based bridge inspection decision-support system that facilitated information visualization and defect marking. Lin et al. (2011) proposed a mobile real-time bridge monitoring system that enabled disaster managers to comprehend the safety of bridges.

-Remote monitoring sensors and surveillance facilities: For various constructions, disaster managers could apply remote monitoring sensors (e.g. seismometers, anemometers, and fiber optic sensors) to simplify inspection processes and obtain the inspection results (Pines, Aktan 2002; Kottapalli et al. 2003). In other words, although the disaster managers are not on disaster sites, they still rapidly realize the structural conditions of constructions (e.g. displacements, velocities, accelerations, forces, temperatures, and acoustic signals). Since the remote monitoring sensors may be distributed in many elements of a construction, disaster managers could use remote surveillance facilities to observe the construction and the site when these sensors warn them of unusual detections (Abeid et al. 2003).
Regarding the use of remote monitoring sensors and surveillance facilities for bridge management, many studies have been conducted. For example, Aktan et al. (2000) showed a pilot health monitoring system for the environmental and live load effects on the Commodore Barry Bridge in Philadelphia, and argued that this system was useful for planning, preparation, and response to disasters. To investigate the damage to long-span bridges during earthquakes and typhoons, Sumitro et al. (2001) presented a new system associated with numerous remote monitoring sensors to obtain key information concerning bridge structural health (e.g. the motion, fatigue, and stress). Chae et al. (2012) developed a wireless sensor network system for suspension bridge health monitoring, and presented the advantages (e.g. low cost, easy maintenance, and stable information communication).

- Computer simulation and 3D graphics: each disaster generally is very different from others; thus, inspecting constructions through experiments on disaster sites is difficult for construction engineers and workers. In contrast, applying computer simulation in a similar inspection is safe, efficient, and fast (Chen et al. 2004; Lu et al. 2004; Marzouk et al. 2007). Furthermore, integrating remote monitoring sensors and computer simulation enhances the accuracy of the inspection results. When disaster managers acquire these results, visualizing the information content as 3D graphics may be a good method, since human beings could synchronously process a large amount of visual information and compare it to textual or numeric information (Russell et al. 2009).

A number of studies are as follows. Based on a catalogue of remote sensing imagery and the Federal Highway Administration (FHWA) databases, Adams et al. (2002) proposed two algorithms (i.e. "Bridge Hunter" and "Bridge Doctor") to perform post-disaster damage bridge assessment for highway bridges. Lu et al. (2004) embedded a 3D-graphics real-time display component into a bridge monitoring system that offered a clear and direct conception regarding the safeties of large-span bridges under typhoons. By incorporating on-site ambient vibration measurement and establishing a 3Dgraphics bridge structure model, Lin et al. (2011) showed the current conditions of the inspected bridge that formulated guidelines for bridge maintenance and seismic hazard prevention.

\section{Study problems}

Based on the literature review, Figure 1 displays the relationship when disaster managers and construction engineers and workers cooperate on bridge management during typhoons and rainstorms. Since the construction engineers and workers have previously installed various remote monitoring sensors and surveillance facilities in bridges, the disaster managers could manage the bridges in the disaster response centers. When typhoons and rainstorms occur, if the disaster managers recognize that the status of the monitored bridges is becoming worse, construction engineers and workers would move to the disaster sites and perform the disaster response. For example, 
after receiving a weather forecast regarding a typhoon, the disaster managers monitor numerous bridges through several electronic water meters. If the rainfall for a bridge reaches the state of alert, the disaster managers investigate the bridge through GIS, and evaluate the possible damage (e.g. bridge collapse and debris flows) through computer simulation. The construction engineers and workers would arrive at the bridge to prevent the damage.

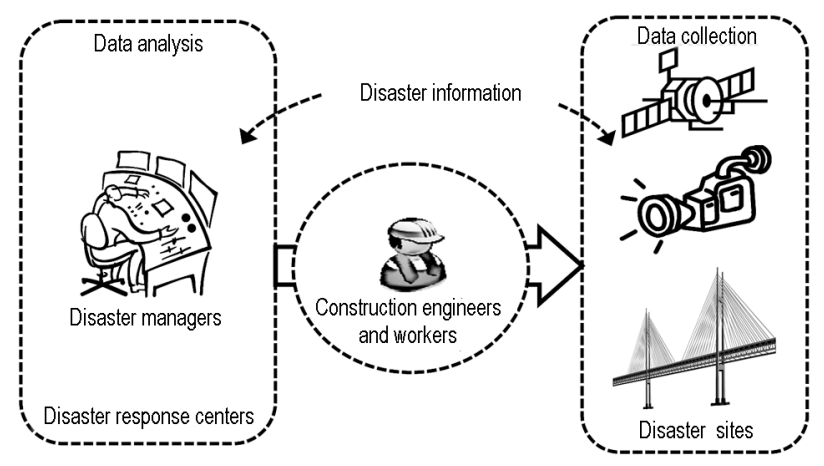

Fig. 1. Disaster response between disaster response centers and disaster sites

However, three problems between the disaster response centers and the disaster sites can cause varying information deficiency (e.g. incomplete, imprecise, fragmentary, unreliable, vague, or contradictory) (MacEachren et al. 2005; Klir 2006). As a result, the efficiency of the disaster response is not as expected. The three problems include:

- Asynchronous information records in GPS and GIS: Various objects (e.g. a river, a mountain, a street, a house, and a bridge) that exist in the earth surface, have individual characteristics. Since these objects are defined as numerous layers, GPS and GIS show the specified information by filtering or integrating these layers. However, when construction engineers and workers discuss disaster response for bridge management with disaster managers, the disaster managers may make inappropriate decisions. One reason is that construction engineers and workers obtain the latest information on disaster sites, while disaster managers use GIS to receive out-of-date information on the disaster response centers. In other words, the information that was previously stored in GIS may not completely fulfill the requirements for the disaster response.

- Unsteady information transmission in remote monitoring sensors and surveillance facilities: remote monitoring sensors and surveillance facilities are the foundation to provide disaster managers the correct conditions of the bridges and the sites in real-time. However, unsteady information transmission can occur when typhoons and rainstorms affect and harm these sensors and facilities, especially monitoring cameras and power supply cables. For example, if the disaster managers observe various bridge sites through remote surveillance facilities during a typhoon, bad weather either hinders the disaster managers from clearly comprehending the received images or suspends the remote surveillance facilities that normally offer services. In order to smoothly transfer the disaster information from the disaster sites to the disaster response centers, construction engineers and workers need to maintain the remote monitoring sensors and surveillance facilities on disaster sites.

- Inaccessible information analysis in computer simulation and 3D graphics: when construction engineers and workers are on disaster sites, the impact for bridges that is caused by typhoons and rainstorms may differ greatly from the pre-testing results that were analyzed by computer simulation and 3D graphics. Based on the site conditions, the construction engineers and workers may attempt to use the similar computer simulation and 3D graphics to analyze the bridges again. However, many computer simulation and 3D graphics are designed for personal computers and laptops (Lipman 2004). Since heavy personal computers and laptops that need much power supply are quite inconvenient at disaster sites, construction engineers and workers have difficulty performing computer simulation and $3 \mathrm{D}$ graphics.

In sum, construction engineers and workers need a beneficial approach. Through this approach, synchronizing information record, steadying information transmission, and accessing information analysis can be accomplished on disaster sites. The emergency response between the disaster sites and disaster response centers in bridge management can be seamless.

\section{Approach}

For the recognized problems, this study proposes a mobile-phone-based approach (i.e. a mobile disaster response system). Unlike personal computers and laptops, mobile phones support many communication protocols (e.g. Global System for Mobile Communications, or GSM; Wideband Code Division Multiple Access, or WCDMA; and Wireless Local Area Network, or WLAN), and offer the advantages of being smart, slim, handy, portable, and electricity-conserving (Tsai et al. 2012). When construction engineers and workers benefit from the proposed approach on disaster sites, the cooperation between the disaster managers and the construction engineers and workers would be effective. The approach consists of three solutions including:

- Mobile GPS- and GIS-based data reports: this solution shortens the procedures of data input and modification, and finally produces accurate and up-todate records. Since construction engineers and workers could dynamically gather the disaster information, the disaster managers could determine the disaster response by retrieving, transferring, updating, manipulating, and analyzing the received disaster information along with GIS (Chen et al. 2004; Enders, Brandt 2007; Sardadi et al. 2008).

When construction engineers and workers employ mobile phones and the embedded GPS to explain the disaster information regarding an impacted bridge, disas- 
ter managers could determine the safety and the suitability of the bridge for future use, schedule the optimal routes to reach the affected disaster areas, or evacuate the stalemated population (Kwan, Lee 2005; Kamat, El-Tawil 2007). Clearly, implementing mobile GPS- and GISbased data reports synchronizes the information records between the disaster response centers and the disaster sites in real-time.

- "Augmented Reality (AR)" based assistance: during typhoons and rainstorms, the installed remote monitoring sensors and surveillance facilities may not work. In order to assure steady information transmission, the construction engineers and workers should understand the locations of the sensors and facilities. When the construction engineers and workers build up a cognitive map and comprehend spatial relationships, maintaining the remote monitoring sensors and surveillance facilities would be easy (Hedley et al. 2002). Using AR-based assistance achieves the above mentioned objective, since the AR-based assistance could superimpose virtual images that involve important information descriptions on the real world (Hammad et al. 2006).

Although Table 1 shows that numerous studies develop their AR-based assistance through an optical seethrough system (Juan, Calatrava 2011), pattern recognition (Shetty, Kolur 2011), or audio (Vazquez-Alvarez et al. 2011), the AR-based assistance in this study relies on global positioning data. For example, as Figure 2 shows, on a disaster site, the construction engineers and workers apply the AR-based assistance to seek a bridge that is the most near to them. After successfully detecting the current location, the AR-based assistance inquires the used database to identify the bridge. In the meantime, the AR-based assistance captures the peripheral images via the embedded cameras, and overlaps the obtained details (e.g. the name and the length) of the bridge upon the images. Since the AR-based assistance represents the infor- mation through the screens of mobile phones, this study reduces excessive operation devices. Therefore, in order to steady information transmission, the construction engineers and workers could correctly aim at the defective remote monitoring sensors and surveillance facilities.

Table 1. AR-based assistance in numerous studies

\begin{tabular}{l|l|l}
\hline Researchers & Approach & \multicolumn{1}{c}{ Concepts } \\
\hline $\begin{array}{l}\text { Juan and } \\
\text { Calatrava } \\
(2011)\end{array}$ & $\begin{array}{l}\text { Optical } \\
\text { see-through } \\
\text { systems }\end{array}$ & $\begin{array}{l}\text { If the used computer vision tech- } \\
\text { niques obtain the position and orien- } \\
\text { tation of a camera with respect to } \\
\text { some markers, virtual objects are } \\
\text { drawn on these markers. }\end{array}$ \\
\hline $\begin{array}{l}\text { Shetty and } \\
\text { Kolur } \\
(2011)\end{array}$ & Pattern & $\begin{array}{l}\text { When the images and objects on the } \\
\text { text pages are recognized, the related } \\
\text { contents are played or augmented on } \\
\text { the display. }\end{array}$ \\
\hline $\begin{array}{l}\text { Vazquez- } \\
\text { Alvarez et al. } \\
(2011)\end{array}$ & Audio & $\begin{array}{l}\text { Using auditory landmarks and 3D } \\
\text { audio spatialization to allow users to } \\
\text { explore the environment. }\end{array}$ \\
\hline
\end{tabular}

- Mobile 3D graphics: recently, high-performance hardware (e.g. processors, memory, and highresolution screens) and rapid-developing software (e.g. application programming interfaces and standards) speed up the application of mobile 3D graphics (Zlatanova, Holweg 2004). Mobile phones also offer an intuitive method to perform information processes, since 3D-graphics objects could be captured, moved, and controlled directly through the embedded touch-enabled screens (Burigat, Chittaro 2005; Yabuki et al. 2006). After this study constructs the mobile 3D graphics, the construction engineers and workers have many opportunities to execute computer simulation and 3D graphics during the response on disaster sites. In other words, inaccessible information analysis would be improved.

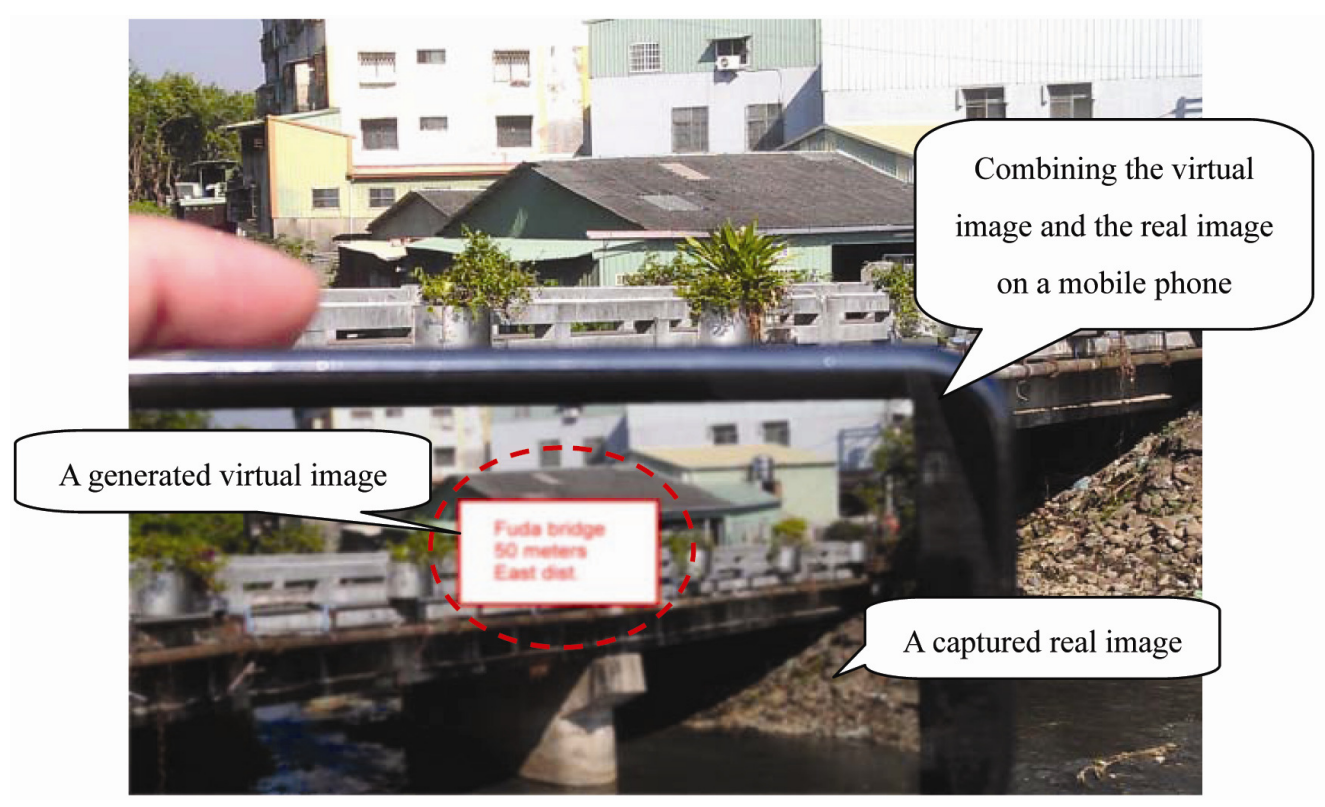

Fig. 2. Recognizing a bridge through AR-based assistance 
Information operation

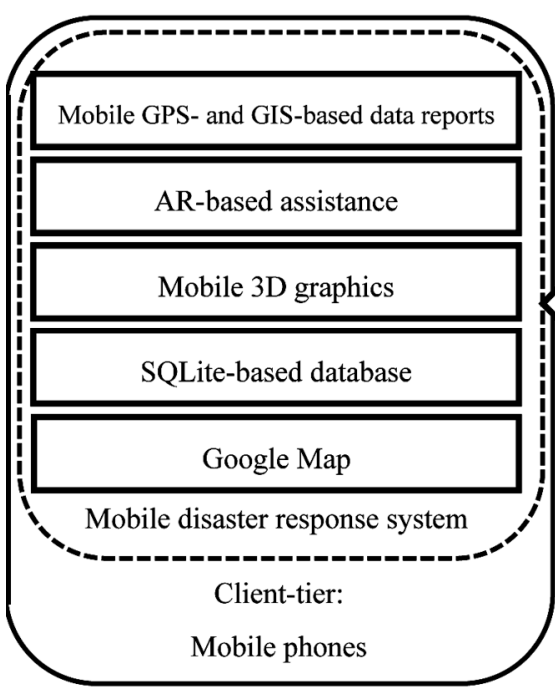

Fig. 3. Three-tier System framework
Information exchange



Information store

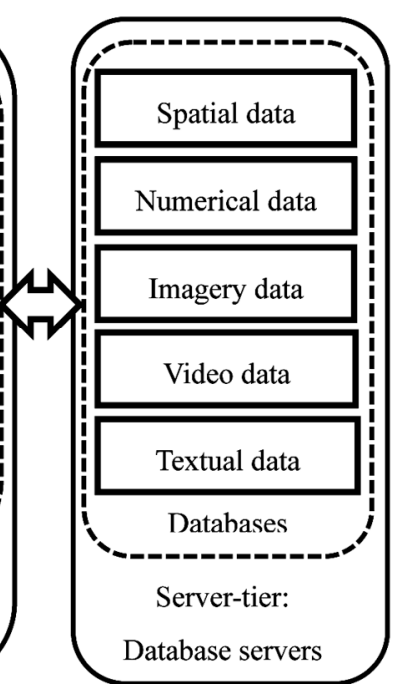

\section{Implementation}

During the implementation, this study adopts a three-tier framework (i.e. the client tier, the middle tier, and the server tier). This framework helps this study to ensure the continuous information flow between construction engineers and workers and disaster managers. Figure 3 displays that the three tiers involve three main information activities (i.e. information operation, information exchange, and information store), respectively.

For the client tier, the mobile disaster response system is based on the Google Android, because many highperformance mobile phones adopt this operation system. This study easily distributes the mobile disaster response system for various construction engineers and workers. When developing the required system components through several information tools (e.g. Java programming language, Google Android development toolkits, and Microsoft ASP.Net toolkits), this study also embeds a mobile database (i.e. a SQLite-based database) and an electronic map platform (i.e. Google Map) into the mobile disaster response system. The mobile database ensures that the information processes can be executed, if the information communication between the disaster sites and disaster response centers is interrupted. The map platform presents the specified geographical information for the construction engineers and workers.

During disasters, the mobile disaster response system supports various information operations on disaster sites, as Figure 4 shows. The construction engineers and workers describe the details of the disasters (e.g. geographical information, disaster photos and disaster descriptions) through the mobile GPS- and GIS-based data reports. Since the mobile disaster response system automatically detects the current locations, this system connects to the nearby remote monitoring sensors and surveillance facilities. If these facilities do not respond to the mobile disaster response system, the AR-based assistance leads the construction engineers and workers to maintain the failed sensors and facilities. Inversely, the construction engineers and workers access the analysis results of the remote monitoring sensors via the mobile 3D graphics, and understand the conditions of the bridge elements (i.e. bridge body, floors, columns, and piers) in real time.

In the middle tier, when the mobile disaster response system delivers disaster information from the construction engineers and workers to the disaster managers, Figure 3 shows that this system would automatically transfer the information into disaster reports based on several information protocols. The protocols include the GeoAPI for manipulating of geographical information based on the international standards; the Web Feature Service (WFS) for offering HTTP-protocols-based geographical features; the Web Processing Service (WPS) for standardizing geospatial processing services; the Keyhole

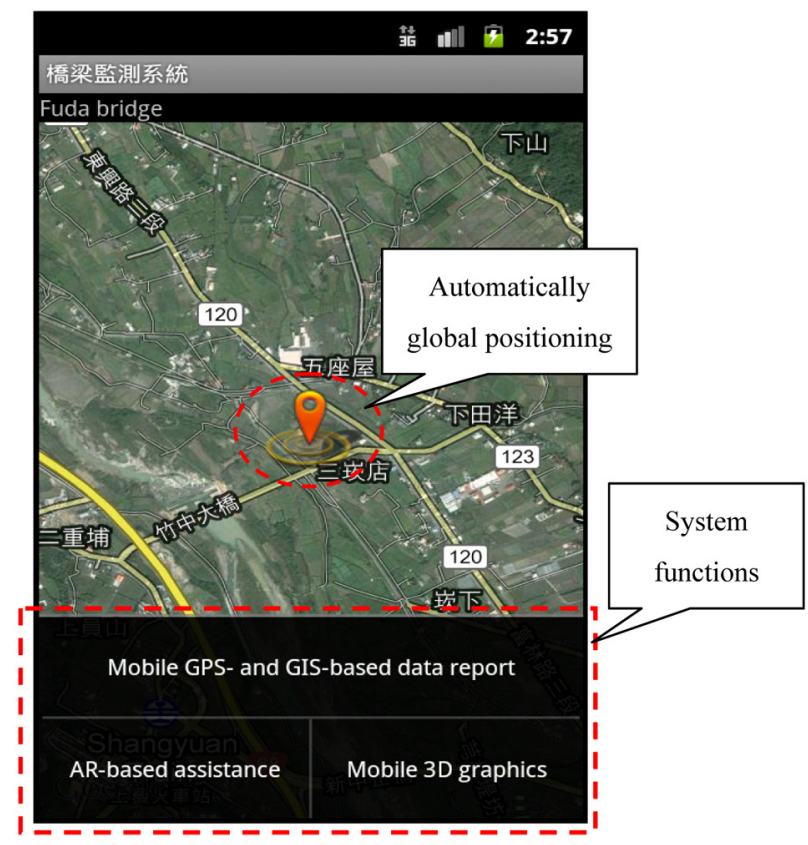

Fig. 4. A screenshot of the mobile disaster response system 
Markup Language (KML) for expressing geographical annotations and visualization; and the OpenGL ES for displaying 3D graphics on mobile phones (Open Geospatial Consortium 2012; Khronos 2012). After the disaster managers receive the disaster reports through disaster management information systems, they obtain useful information. Therefore, information exchange between the disaster sites and disaster response centers is achieved.

Moreover, the server tier mainly takes charge of storing the information. Figure 3 shows that several database servers save the received data and offer the inquired information, such as the spatial data, numerical data, imagery data, video data, and textual data. The database servers on disaster response centers are Microsoft SQL Server Version 2008. For example, on disaster sites, the construction engineers and workers deliver to disaster managers some photos regarding the bridge collapse. The database servers store the photos into an imagery database and record the spatial coordinates of the sender locations into a spatial database. The disaster managers could efficiently manage the received disaster reports.

\section{Tests}

During a simulated scenario along with a strong gale and a torrential rain, three concrete bridges in Northern Taiwan were affected. Based on the standard operating procedure for typhoons and floods (Water Resources Bureau 2012), when the construction engineers and workers gathered the disaster information regarding the three bridges on the disaster sites, the disaster managers would analyze the information in the disaster response centers.

This study classified the tests into two stages - "Before (the disaster response without the mobile disaster response system)" and "After (the disaster response with the mobile disaster response system)". Table 2 shows the used methods in the two stages. The construction engineers and workers and disaster managers participating in the tests not only had two-year experience regarding disaster response in bridge management, but also had been trained to use the mobile disaster response system for two months. Table 3 presents the test results, including:

-Reporting the disaster information: for the Before stage, the construction engineers and workers reported the disaster information to the disaster managers through speech communication and mobile phones. In contrast, during the After stage, Figure 5 shows that the construction engineers and workers applied the mobile GPS- and GIS-based data reports to record and deliver the disaster information.
Table 2. The used methods in the Before and After stages

\begin{tabular}{l|l|l}
\hline & \multicolumn{1}{|c|}{ The Before stage } & The After stage \\
\hline $\begin{array}{l}\text { Reporting the disas- } \\
\text { ter information }\end{array}$ & $\begin{array}{l}\text { Speech communication } \\
\text { via mobile phones }\end{array}$ & $\begin{array}{l}\text { Mobile GPS- and } \\
\text { GIS-based data } \\
\text { reports }\end{array}$ \\
\hline $\begin{array}{l}\text { Maintaining the } \\
\text { remote surveillance } \\
\text { facilities }\end{array}$ & $\begin{array}{l}\text { Paper documents and } \\
\text { manual discovery }\end{array}$ & $\begin{array}{l}\text { AR-based assis- } \\
\text { tance }\end{array}$ \\
\hline $\begin{array}{l}\text { Blocking out the } \\
\text { bridges }\end{array}$ & $\begin{array}{l}\text { Speech communication } \\
\text { via mobile phones }\end{array}$ & $\begin{array}{l}\text { Mobile 3D } \\
\text { graphics }\end{array}$ \\
\hline
\end{tabular}

This study measured the operation time on the three disaster sites, when the disaster managers confirmed a record regarding the disaster information with the construction engineers and workers. Based on Table 3, the average operation time of the Before stage was 7 minutes and that of the After stage was 3.3 minutes. Due to that, the construction engineers and workers did not spend much time on explaining the details of the disasters for the disaster managers, the mobile disaster response system was better for reporting the disaster information.

- Maintaining the remote surveillance facilities: in the Before stage, the disaster managers recognized some failed remote surveillance facilities, and asked the construction engineers and workers to maintain these surveillance facilities via speech communication and mobile phones. After checking some paper documents regarding the distribution of the remote surveillance facilities, the construction engineers and workers repaired the surveillance facilities by manually seeking the locations of the surveillance facilities.

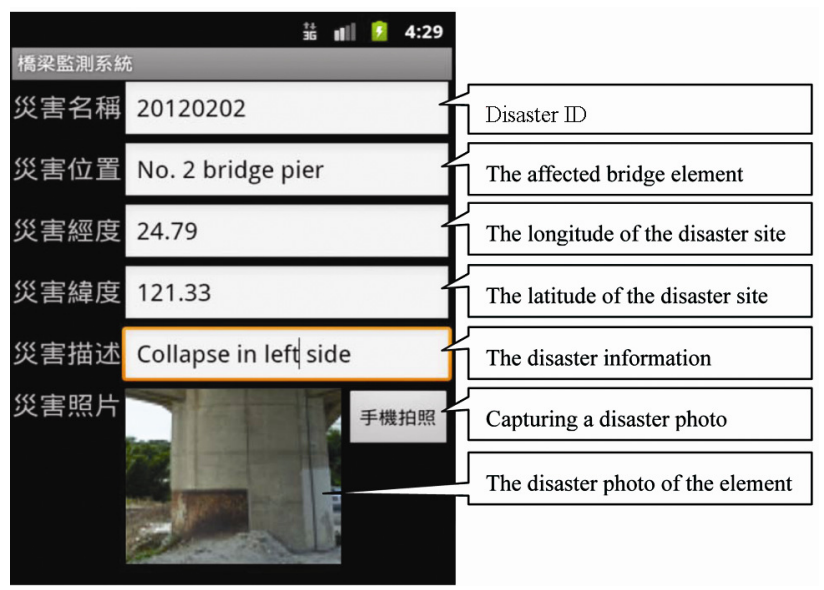

Fig. 5. A screenshot of mobile GPS- and GIS-based data reports

Table 3. Test results

\begin{tabular}{c|c|c|c|c|c|c}
\hline & \multicolumn{5}{c}{ Tests } \\
\cline { 2 - 7 } & \multicolumn{2}{|c}{ Reporting the disaster information } & Maintaining the remote surveillance facilities & \multicolumn{2}{c}{ Blocking out the bridges } \\
\hline \multirow{2}{*}{ Disaster site } & Before & After & Operation time (minutes) & After & Before & After \\
\cline { 2 - 8 } & 7 & 3 & 13 & 4 & 10 & 3 \\
\hline 1 & 6 & 3 & 15 & 5 & 9 & 10 \\
\hline 3 & 8 & 4 & 19 & 4 & 9.7 & 3 \\
\hline Average & 7 & 3.3 & 15.7 & 4.3 & 3 \\
\hline
\end{tabular}


For the After stage, because the mobile disaster response system identified the latitude and longitude of the construction engineers and workers, Figure 6 shows that the AR-based assistance inquired the mobile database, and presented the details of a failed surveillance facility (e.g. the identified number, the category, and the location). Also, although the construction engineers and workers performed the tests at night, the AR-based assistance worked well.



Fig. 6. Using AR-based assistance on disaster sites at night

During the two stages, this study determined the operation time from when the construction engineers and workers looked for the failed remote surveillance facility until they arrived on the scene. On average, Table 3 shows that the Before stage took 15.7 minutes and the After stage required 4.3 minutes. Clearly, while the ARbased assistance simplified the time-consuming document investigation and manual discovery for the remote surveillance facilities, the construction engineers and workers maintained the surveillance facilities rapidly and correctly.

-Blocking out the bridges: regarding the Before stage, based on the remote monitoring sensors, the disaster managers investigated the health of the three bridges. If it became worse, in order to avoid the collapse of the bridge elements, the disaster managers used mobile phones to communicate with the construction engineers and workers, and notified them to block out the bridges.

In the After stage, the mobile disaster response system actively connected to the remote monitoring sensors. When the construction engineers and workers recognized any exceptional condition, they could preliminarily inform the disaster managers and block out the bridges. For example, Figure 7 shows that the mobile 3D graphics highlighted a bridge floor in red color, since this bridge element had the potential to collapse.

This study assessed the operation time from when the remote monitoring sensors alerted the collapse potential of bridge elements until the construction engineers and workers blocked out the bridges. The average operation time of the After stage (3 minutes) was shorter than that of the Before stage ( 9.7 minutes), as Table 3 shows.
Therefore, due to the fact that the construction engineers and workers did not passively wait for the decisions of the disaster managers, the mobile disaster response system strengthened the cooperation between the disaster sites and the disaster response centers.

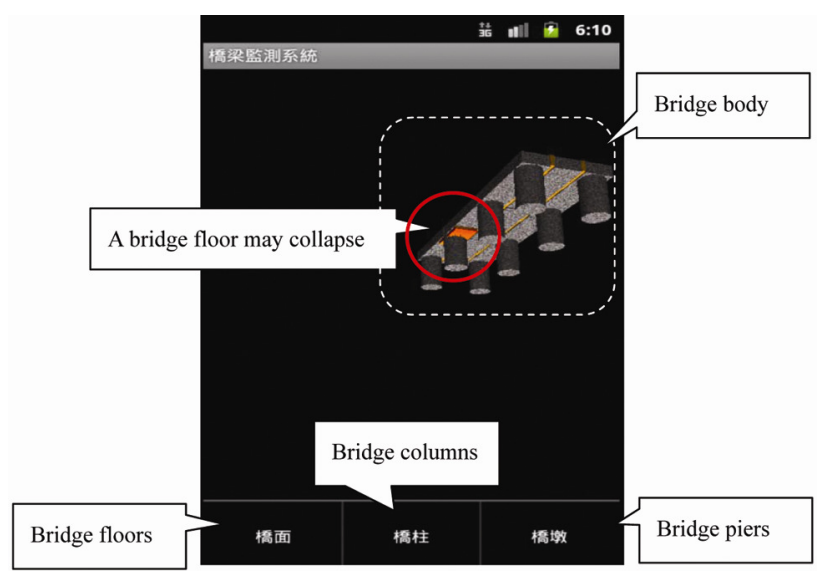

Fig. 7. Confirming bridge health through mobile 3D graphics

\section{Discussions}

Based on the tests on disaster sites, the mobile disaster response system helped construction engineers and workers to effectively perform disaster response in bridge management. The main outcomes include:

- Offering accurate disaster information in real time: the mobile disaster response system not only reports sudden disaster information, but also offers precise disaster locations. In the meantime, the information regarding the disaster sites is presented well and truly. For example, the construction engineers and workers could collect the disaster information based on the specified inspection spots (e.g. bridge floors and piers). Compared to the previously stored information in GIS, the delivered disaster information represents rapid changes of bridges during typhoons and rainstorms. To respond when receiving disaster information, the disaster managers have the ability to make appropriate decisions.

-Enhancing on-site assistance based on the peripheral images of the disaster sites: if the construction engineers and workers have no idea regarding the locations of the remote monitoring sensors and surveillance facilities, maintaining these sensors and facilities on disaster sites is difficult, especially at night. In other words, it is important that the construction engineers and workers comprehend the spatial relationship among the sensors, facilities and bridges. The mobile disaster response system generates virtual images, and overlaps them upon the peripheral images to form an on-site guide. Therefore, the construction engineers and workers could save time in looking for failed remote monitoring sensors and surveillance facilities.

-Improving the information analysis on disaster sites: In contrast to the time-consuming information analysis through paper-based constructional design doc- 
uments and drawings, the mobile disaster response system collects the data from the remote monitoring sensors, and represents the results through the mobile 3D graphics. The construction engineers and workers conveniently understand the relationship between the disaster impact and the bridge elements. For example, the construction engineers and workers need six constructional design draws (i.e. top-, bottom-, left-, right-, forward-, and back-view) to comprehend a bridge and annotate the disaster losses in the draws. In contrast, the mobile disaster response system enables the construction engineers and workers to reach the identical comprehension by rotating and zooming-in/out the 3D-graphics bridge. Obviously, the mobile disaster response system is a powerful tool on disaster sites.

\section{Conclusions}

Extreme climate conditions associated with frequent hydro-meteorological disasters recently have impacted many countries and caused inestimable damage. When various disasters occur, since bridges are necessary for the relief work, the effective disaster response in bridge management has become important. However, although numerous IT-based applications are available in disaster management, three problems (i.e. asynchronous information record, unsteady information transmission, and inaccessible information analysis) still hinder construction engineers and workers from responding to disaster sites.

Therefore, this study proposes a mobile disaster response system by integrating several mobile information techniques. The applied mobile GPS- and GIS-based data reports simplify information generation, AR-based assistance enhances information representation, and mobile $3 \mathrm{D}$ graphics accelerates information processes. Based on the tests, the construction engineers and workers successfully delivered the disaster information through mobile GPS- and GIS-based data reports; rapidly maintained remote monitoring sensors and surveillance facilities through the AR-based assistance; and correctly assessed the affected bridges and their elements through mobile $3 \mathrm{D}$ graphics. This study not only improves the recognized problems but also promotes the disaster response for bridge management.

For future research, in addition to bridges, a number of facilities (e.g. highways and dams) are important in a variety of disasters. In order to increase the effectiveness of the mobile disaster response system, this system should support different facilities and involve a knowledge-based expert system. Thus, in different scenarios, construction engineers and workers and disaster managers could adopt appropriate strategies for disaster management.

\section{Acknowledgements}

The authors would like to thank all members in the Research Center for Hazard Mitigation and Prevention, National Central University. During the period of this study, the financial support came from NCU100G901-11 and NCU101G901-11.

\section{References}

Abeid, J.; Allouche, E.; Arditi, D.; Hayman, M. 2003. PHOTONET II: a computer-based monitoring system applied to project management, Automation in Construction 12(5): 603-616. http://dx.doi.org/10.1016/S0926-5805(03)00042-6

Adams, B.; Huyck, C.; Mansouri, B.; Eguchi, R.; Shinozuka, M. 2002. Post-disaster bridge damage assessment, in Proceedings of the $15^{\text {th }}$ Pecora Conference: Integrating Remote Sensing at the Global, Regional, and Local Scale, Denver, Colorado.

Aktan, A. E.; Catbas, F. N.; Pervizpour, M.; Kulcu, E.; Grimmelsman, K.; Barrish, R.; Qin, X. 2000. Real-time bridge health-monitoring for management, in $2^{\text {nd }}$ Workshop on Advanced Technologies in Urban Earthquake Disaster Mitigation, Kyoto, Japan.

Burigat, S.; Chittaro, L. 2005. Location-aware visualization of VRML models in GPS-based mobile guides, in Proceedings of the Tenth International Conference on $3 D \mathrm{Web}$ Technology, 57-64.

Chae, M. J.; Yoo, H. S.; Kim, J. Y.; Cho, M. Y. 2012. Development of a wireless sensor network system for suspension bridge health monitoring, Automation in Construction 21: 237-252.

http://dx.doi.org/10.1016/j.autcon.2011.06.008

Chen, A. Y.; Peña-Mora, F.; Ouyang, Y. 2011. A collaborative GIS framework to support equipment distribution for civil engineering disaster response operations, Automation in Construction 20: 637-648.

http://dx.doi.org/10.1016/j.autcon.2010.12.007

Chen, Y. Q.; Ding, X. L.; Shi, W. Z. 2004. Geomatics technologies for hazards mitigation, Journal of Geospatial Engineering 6(2): 1-12.

Chen, L.-C. 2011. Highlights of hydro-meteorological disaster preparedness and response, City Development 11: 8-38.

Enders, A.; Brandt, Z. 2007. Using geographic information system technology to improve emergency management and disaster response for people with disabilities, Journal of Disability Policy Studies 17(4): 223-229. http://dx.doi.org/10.1177/10442073070170040501

Federal Emergency Management Agency [online], [cited 2 February 2012]. 2010. Available from Internet: http:// www.fema.gov/pdf/about/pub1.pdf

Hammad, A.; Zhang, C.; Hu, Y.; Mozaffari, E. 2006. Mobile model-based bridge lifecycle management system, Computer-Aided Civil and Infrastructure Engineering 21: 530-547. http://dx.doi.org/10.1111/j.1467-8667.2006.00456.x

Hedley, N. R.; Billinghurst, M.; Postner, L.; May, R.; Kato, H. 2002. Explorations in the use of augmented reality for geographic visualization, Presence: Teleoperators and Virtual Environments 11(2): 119-133. http://dx.doi.org/10.1162/1054746021470577

Juan, M. C.; Calatrava, J. 2011. An augmented reality system for the treatment of phobia to small animals viewed via an optical see-through HMD: comparison with a similar system viewed via a video see-through HMD, International Journal of Human-Computer Interaction 27(5): 436-449. http://dx.doi.org/10.1080/10447318.2011.552059 
Kamat, V. R.; El-Tawil, S. 2007. Evaluation of augmented reality for rapid assessment of earthquake-induced building damage, Journal of Computing in Civil Engineering 21(5): 303-310.

http://dx.doi.org/10.1061/(ASCE)0887-3801(2007)21:5(303)

Khronos [online], [cited 2 February 2012]. Available from Internet: http://www.khronos.org/opengles

Kottapalli, V. A.; Kiremidjian, A. S.; Lynch, J. P.; Carryer, E. D.; Kenny, T. W.; Law, K. H.; Lei, Y. 2003. Two-tiered wireless sensor network architecture for structural health monitoring, in Proceedings of the International Symposium on Smart Structures and Materials 5057: 8-19.

Klir, G. J. 2006. Uncertainty and information foundations of generalized information theory. New Jersey: John Wiley \& Sons, Inc.

Kwan, M.-P.; Lee, J. 2005. Emergency response after 9/11: the potential of real-time 3D GIS for quick emergency response in micro-spatial environments, Computers, Environment and Urban Systems 29: 93-113. http://dx.doi.org/10.1016/j.compenvurbsys.2003.08.002

Lin, Y.-B.; Chang, K.-C.; Chen, C.-C.; Wong, S.-C.; Lee, L.-S.; Wang, Y.-K.; Gu, M.-H. 2011. Integrating real-time bridge scouring monitoring system with mobile locationbased services, International Journal of Automation and Smart Technology 1(2): 51-62. http://dx.doi.org/10.5875/ausmt.v1i2.127

Lipman, R. R. 2004. Mobile 3D visualization for steel structures, Automation in Construction 13: 119-125. http://dx.doi.org/10.1016/j.autcon.2003.08.008

Lu, X.-Z.; Yang, N.; Jiang, J. 2004. Application of computer simulation technology for structure analysis in disaster, Automation in Construction 13: 597-606. http://dx.doi.org/10.1016/j.autcon.2004.04.002

MacEachren, A. M.; Robinson, A.; Hopper, S.; Gardner, S.; Murray, R.; Gahegan, M.; Hetzler, E. 2005. Visualizing geospatial information uncertainty: what we know and what we need to know, Cartography and Geographic Information Science 32(3): 139-160. http://dx.doi.org/10.1559/1523040054738936

Marzouk, M.; El-Dein, H. Z.; El-Said, M. 2007. Application of computer simulation to construction of incremental launching bridges, Journal of Civil Engineering and Management 13(1): 27-36.

Open Geospatial Consortium [online], [cited 2 February 2012]. Available from Internet:

http://www.opengeospatial.org/standards

Pines, D.; Aktan, E. 2002. Status of structural health monitoring of long-span bridges in the United States, Progress in Structural Engineering and materials 4(4): 372-380. http://dx.doi.org/10.1002/pse.129
Russell, A. D.; Chiu, C.-Y.; Korde, T. 2009. Visual representation of construction management data, Automation in Construction 18: 1045-1062. http://dx.doi.org/10.1016/j.autcon.2009.05.006

Sardadi, M. M.; Rahim, M.; Jupri, Z.; bin Daman, D. 2008. Mobile geographical information system and it latest problems and issues in the database area, in 5th Malaysian Remote Sensing and GIS Conference Exhibition, Kuala Lumpur, Malaysia.

Shetty, C. K. G.; Kolur, M. 2011. Interactive e-learning system using pattern recognition and augmented reality, Journal of Educational and Social Research 1(4): 21-29.

Sumitro, S.; Okamoto, T.; Matsui, Y.; Fujii, K. 2001. Long span bridge health monitoring system in Japan, in Proceedings of SPIE, 3 August 2001, 4337: 517-524. http://dx.doi.org/10.1117/12.435628

Tsai, M.-K.; Lee, Y.-C.; Lu, C.-H.; Chen, M.-H.; Chou, T.-Y.; Yau, N.-J. 2012. Integrating geographical information and augmented reality techniques for mobile escape guidelines on nuclear accident sites, Journal of Environmental Radioactivity 109: 36-44. http://dx.doi.org/10.1016/j.jenvrad.2011.12.025

Vazquez-Alvarez, Y.; Oakley, I.; Brewster, S. A. 2011. Auditory display design for exploration in mobile audioaugmented reality, Personal and Ubiquitous Computing 16(8): 987-999. http://dx.doi.org/10.1007/s00779-011-0459-0

Wardhana, K.; Hadipriono, F. C. 2003. Analysis of recent bridge failures in the United States, Journal of Performance of Constructed Facilities 17(3): 144-150. http://dx.doi.org/10.1061/(ASCE)0887-3828(2003)17:3(151)

Water Resources Bureau [online], [cited 2 February 2012]. Available from Internet: http://www.tycg.gov.tw/site/site_index.aspx?site_content_ $\mathrm{sn}=4115$

Wong, K. Y.; Man, K. L.; Chan, W. Y. 2001. Monitoring Hong Kong's bridges: real-time kinematic spans the gap, GPS World, July. 8 p.

Yabuki, N.; Machinaka, H.; Zhantao, L. 2006. Virtual reality with stereoscopic vision and augmented reality to steel bridge design and erection, in Proceedings of Joint International Conference on Computing and Decision Making in Civil and Building Engineering, 14-16 June 2006, Montréal, Canada.

Zlatanova, S.; Holweg, D. 2004. 3D geo-information in emergency response: a framework, in Proceedings of the Fourth International Symposium on Mobile Mapping Technology, 29-31 March 2004, Runming China.

Ming-Kuan TSAI. He is a Assistant Research Fellow of Research Center for Hazard Mitigation and Prevention at the National Central University (NCU), Taiwan. His research focuses on the integration of information technology, civil engineering, construction management, and disaster management.

Nie-Jia YAU. He is a Professor of Graduate Institute of Construction Engineering and Management at the National Central University (NCU), Taiwan. He is also the Director of Research Center for Hazard Mitigation and Prevention at NCU. His research interests include schedule delay analysis, construction disputes resolution, build-operate-transfer contracts, bridge management system, and disaster prevention information system. 